Vol. 8, Issue 12, December 2021

DOI: $10.17148 / I A R J S E T .2021 .81255$

\title{
Thermal Buckling of Three Dimensional FG Plate
}

\author{
Mrinal Gautam $^{1}$, Manish Chaturvedi ${ }^{2}$ \\ University Department, Mechanical Engineering, Rajasthan Technical University, \\ Akelgarh, Kota, Rajasthan, 324010, India ${ }^{1,2}$
}

\begin{abstract}
Thermal buckling is performed for Clamped Free Free Free (CFFF) three dimensional functionally graded plate. It is estimated that each plate's material property varies in axial, longitudinal and thickness direction by power law distribution. COMSOL software was used to finite element analysis. The effect on critical buckling temperature, such as power exponent and boundary conditions on FGM plate are considered.
\end{abstract}

Keywords: Functionally Graded Material Plate; Thermal Buckling Analysis; Power Law; Finite Element Method

\section{INTRODUCTION}

Functionally graded material (FGM) is characterized by a compositional gradient of one material into another, which is totally different from the conventional composite materials, which are either homogeneous mixtures that involve a compromise between the properties of the component materials, or two different materials joined together as in the case of laminate composite materials. Functionally graded materials are materials that are designed to meet varying functionalities $[1,2]$.

Swaminathan [3] reviewed thermo-mechanical buckling analysis of FGPs briefly in a subsection of a wide review that also contains stress and vibration analysis. Nano-FGP and micro-FGPs have been studied for thermo-mechanical buckling by many researchers, for example [4].

Aydogdu [5] studied the conditions for bifurcation buckling to exist in the case of FGPs; concluding that for unsymmetrical FGP, under only in-plane compression load, bifurcation can only occur when all edges are clamped. Gao et.al [6] proposed the nonlocal strain graded theory theoretical frameworks. , Zenkour and Mashat [7] investigated the thermal buckling of ceramic-metal FGM plates based on the sinusoidal shear deformation plate theory (SPT). Malekzadeh [8] investigated the three-dimensional thermal buckling of functionally graded arbitrary straight-sided quadrilateral plates based on the dierential quadrature method.

\section{PROPERTY DISTRIBUTION}

Consider three- dimensional FGM plate with a width $b$, length $a$, and thickness $h$. The FG plate is made up of two parts: metal and ceramic. In present work, property distribution in $\mathrm{x}, \mathrm{y}$ and $\mathrm{z}$ direction. $\mathrm{n}_{\mathrm{x}}, \mathrm{n}_{\mathrm{y}}$ and $\mathrm{n}_{\mathrm{z}}$ are the gradient index [9].

$$
\begin{array}{r}
E(z)=\left(E_{c}-E_{m}\right) V_{c}+E_{m} \\
V_{c}=\left(\frac{x}{a}\right)^{n_{x}}\left(\frac{y}{b}\right)^{n_{y}}\left(\frac{z}{h}+\frac{1}{2}\right)^{n_{z}}
\end{array}
$$

\section{FEM MODELLING}

In present study, tri directional FGM plate dimensions are taken i.e. width $b=1 \mathrm{~m}$, length $\mathrm{a}=1 \mathrm{~m}$ and thickness $\mathrm{h}=0.01 \mathrm{~m}$. Material properties are for metal phase ( Aluminium) $\mathrm{E}_{\mathrm{m}}=70 X 10^{9} \mathrm{~Pa}, \rho_{\mathrm{m}}=2700 \mathrm{~kg} / \mathrm{m}^{3}, \boldsymbol{\alpha}_{\mathrm{m}}=\mathbf{2 3 X 1 0 ^ { ( - 6 ) }} 1 / \mathrm{K} \kappa_{\mathrm{m}}=204$ W/m.K and Ceramic phase (Alumina $\left.\left(\mathrm{Al}_{2} \mathrm{O}_{3}\right)\right) \mathrm{E}_{\mathrm{c}}=380 \mathrm{X} 10^{9} \mathrm{~Pa}, \rho_{\mathrm{c}}=3900 \mathrm{~kg} / \mathrm{m}^{3}, \boldsymbol{\alpha}_{\mathbf{c}}=\mathbf{7 . 4} \mathbf{X 1 0}^{(-6)} 1 / \mathrm{K}, \kappa_{\mathrm{c}}=10.4$ W/m.K. Poission ratio and heat capacity for specific heat are taken $v=0.3$ and $C_{p}=900 \mathrm{~J} / \mathrm{kg} . \mathrm{K}$. 
International Advanced Research Journal in Science, Engineering and Technology

Vol. 8, Issue 12, December 2021

DOI: $10.17148 /$ IARJSET.2021.81255

\section{RESULTS}

The FGM plate is being considered for the validation research for reference [10].

Table 1: For tri-directional $\mathrm{Al}_{2} \mathrm{O}_{3} / \mathrm{Al}$ Clamped FG plate $(\mathrm{a} / \mathrm{b}=1)$, Critical Buckling Temperature $\left(\Delta \mathrm{T}_{\text {cr }}\right.$

\begin{tabular}{|c|c|c|c|c|c|c|c|}
\hline & \multirow{2}{*}{$\begin{array}{l}\text { Boundary } \\
\text { Conditions }\end{array}$} & \multirow{2}{*}{$\mathrm{a} / \mathrm{h}$} & \multicolumn{5}{|l|}{$\left(\Delta \mathrm{T}_{\mathrm{cr})}\right.$} \\
\hline & & & $\mathrm{k}=0$ & $\mathrm{k}=0.5$ & $\mathrm{k}=1$ & $\mathrm{k}=2$ & $\mathrm{k}=5$ \\
\hline $\begin{array}{l}\text { Present } \\
\text { Study }\end{array}$ & CCCC & 50 & 180.12 & 103.03 & 83.821 & 74.256 & 74.61 \\
\hline $\begin{array}{l}\text { Zao et.al } \\
\text { (2009) }\end{array}$ & $\mathrm{CCCC}$ & 50 & 175.817 & 99.162 & 82.357 & 71.013 & 74.591 \\
\hline
\end{tabular}
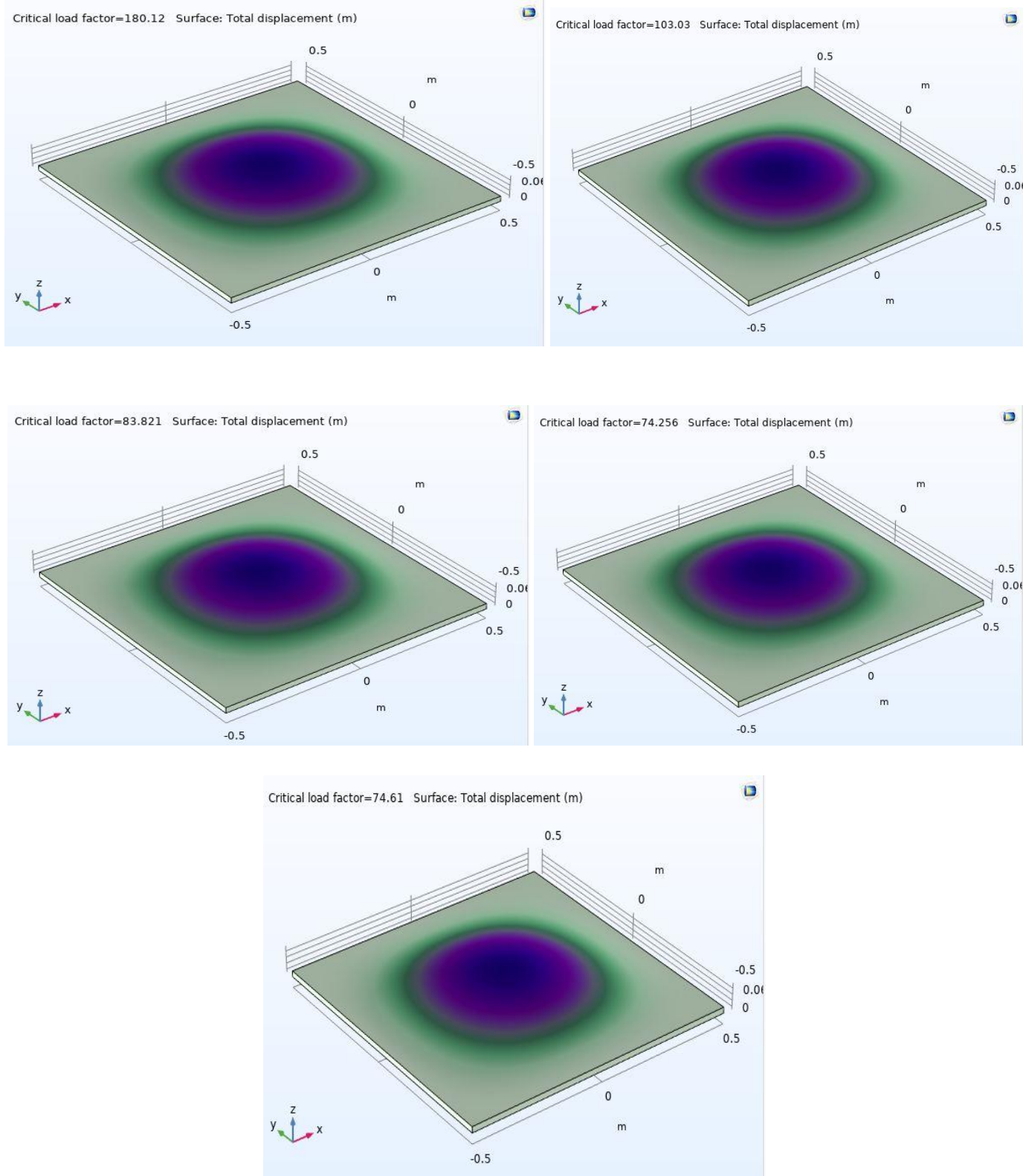

Fig 2: Thermal buckling mode shapes for CCCC Functionally Graded plate $(\mathrm{k}=0,0.5,1,2,5 \&$ a/b=1) at critical buckling temperature $\left(\Delta \mathrm{T}_{\mathrm{cr}}\right)$ the thickness ratios $(\mathrm{a} / \mathrm{h}=50)$ 


\title{
International Advanced Research Journal in Science, Engineering and Technology
}

\author{
Vol. 8, Issue 12, December 2021
}

DOI: $10.17148 /$ IARJSET.2021.81255

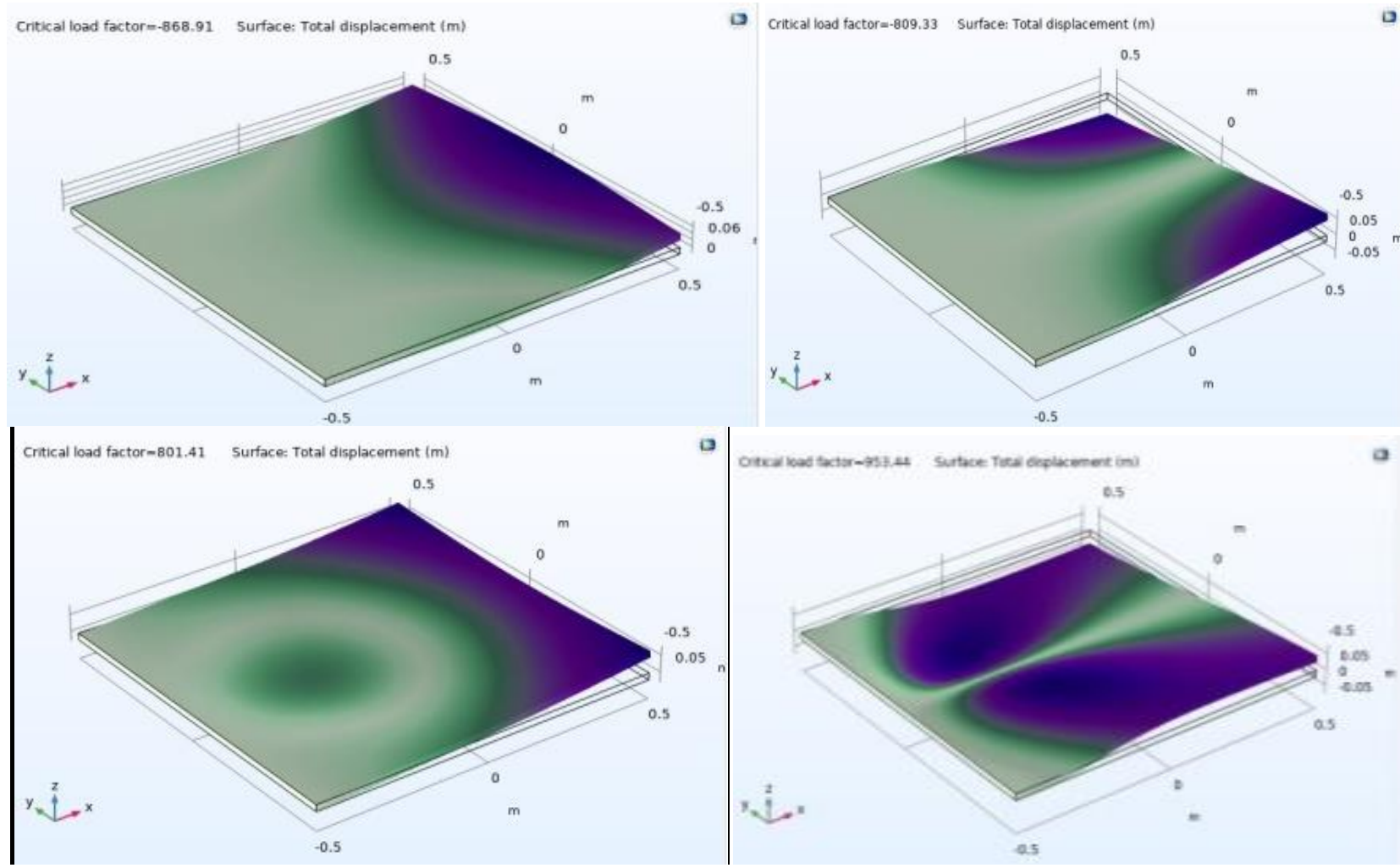

Fig 2: Thermal buckling mode shapes for CFFF Functionally Graded plate $\left(a / b=1 \& k_{x}=2, k_{y}=2, k_{z}=1\right)$ at critical buckling temperature $\left(\Delta \mathrm{T}_{\mathrm{cr}}\right)$ the thickness ratios $(\mathrm{a} / \mathrm{h}=50)$

As a results Shown (Table 2-3 \& Figure 4-7), Thermal buckling mode shapes for Functionally Graded plate $(\mathrm{a} / \mathrm{b}=1 \&$ $\left.\mathrm{k}_{\mathrm{x}}=2, \mathrm{k}_{\mathrm{y}}=2, \mathrm{k}_{\mathrm{z}}=1\right)$ at critical buckling temperature $\left(\Delta \mathrm{T}_{\mathrm{cr}}\right)$ the thickness ratios $(\mathrm{a} / \mathrm{h}=100$ and $\mathrm{a} / \mathrm{h}=50)$. In that results, CCCC boundary conditions higher critical buckling temperature than CFCF in first two mode shapes and lower critical buckling temperature than CFFF in 3 and 4 mode shapes.

\section{CONCLUSION}

The behaviour of thermal buckling of a CFFF functionally graded plate under uniform temperature loading is examined. In a functionally graded plate, property distributions are power law in thickness, length, and width directions. The current representation is created using the COMSOL Multiphysics FEM programme. The current values are compared to the published values. We found that as the gradient index increases, the critical buckling temperature in the CFFF Functionally plate decreases.

\section{REFERENCES}

[1] Niino, M., Hirai, T., Watanabe, R.: The functionally gradient materials. J. Jpn. Soc. Compos. Mater. 13, $257-264$ (1987).

[2]. Report on "Fundamental study on relaxation of thermal stress for high-temperature material by tailoring the graded structure". Department of Science and Technology Agency (1992).

[3]. Swaminathan, K., Naveenkumar, D.T., Zenkour, A.M., Carrera, E., Stress, vibration and buckling analyses of FGM plates: A state of the art review. Composite Structures, 120, 10-31, 2015.

[4]. Aghazadeh, R., Dag, S., Cigeroglu, E., Thermal effect on bending, buckling and free vibration of functionally graded rectangular micro-plates possessing a variable length scale parameter. Microsystem Technologies, 1-24, 2018.

[5]. Aydogdu [85] studied the conditions for bifurcation buckling to exist in the case of FGPs; concluding that for unsymmetrical FGP, under only inplane compression load, bifurcation can only occur when all edges are clamped.

[6].Gao, Yang, Wan-shen Xiao, and Haiping Zhu. "Nonlinear thermal buckling of bi-directional functionally graded nanobeams." Structural Engineering and Mechanics 71.6, 669-682 (2019).

[7] .A. M. Zenkour and D. S. Mashat, “Thermal buckling analysis of ceramic-metal functionally graded plates," Nat. Sci., vol. 2, pp. 968-978, 2010

[8]. P. Malekzadeh, "Three-dimensional thermal buckling analysis of functionally graded arbitrary straight-sided quadrilateral plates using dierential quadrature method," Compos. Struct., vol. 93, pp. 246-1254, 2011

[9]. Do, Dieu TT, H. Nguyen-Xuan, and Jaehong Lee. "Material optimization of tri- directional functionally graded plates by using deep neural network and isogeometric multimesh design approach." Applied Mathematical Modelling 87 (2020): 501-533.

[10]. Zhao, Xin, Y. Y. Lee, and Kim Meow Liew. "Mechanical and thermal buckling analysis of functionally graded plates." Composite Structures 90.2 (2009): 161-171. 